\title{
Improving Fruit and Vegetable Consumption in Elementary School Students: A Systematic Review of Interventions
}

\author{
Seyed Mohammad Mehdi Hazavehei, Seyedeh Zeinab Hashemi and Sara Shahabadi
}

Department of Public Health, Public Health School, Hamadan University of Medical Sciences, Hamadan, Iran

\begin{abstract}
Introduction: Less than 15\% of the 4 to 8 -year old children consume the recommended servings of fruit and vegetables (FV). Early years of life play an important role in establishing healthy eating habits. School is an appropriate setting for healthy eating habits interventions. The purpose of this systematic review is evaluation of school-based interventions to improve FV consumption in elementary school students.

Methods: In this systematic review, we performed a search in several databases such as PubMed, Web of Science, Education Resources Information Center (ERIC), Science Direct and Google Scholar. Studies published between January 2005 and December 2012 were included. In examining the studies, we focused on design, strategies and outcomes of the interventions.

Results: Eleven studies met the inclusion criteria. Interventions in these three classifications (gardening and education, educational programs and providing FV) have positive effects on children's FV intake. Multi-component education is more effective than other cases in children willingness for FV consumption. Gardening strategies: participating in handson gardening experiences, engaging in gardening challenges and preparing a party by student's garden products. Educational strategies: nutrition education classes, electronic learning by using the popular cartoon characters and child actors as symbolic role models and strategies to improve family awareness like series of newsletters for parents and homework tasks for parents and children. Providing strategies: providing fee-based or free FV at school.
\end{abstract}

Conclusion: Long-term multi-component (gardening, education and providing FV) interventions with the application of behavioral change theories and models are effective to reach the expected results.

Keywords: Intake, Eating, Increasing, Primary students, School children, Children.

\section{INTRODUCTION}

One of the most important components of a healthy diet is FV consumption, and recent epidemiological studies indicate that regular intake of sufficient amount can be effective in the prevention of chronic diseases such as cardiovascular disease, stroke and some cancers [1-4]. Moreover, there is significant association between low consumption of FV with perceived poor mental health status, previous diagnosis of a mood disorder and anxiety disorder [5]. Nearly 2.635 million of worldwide deaths per year are attributable to insufficient FV intake. Improving daily individual FV intake to up to $600 \mathrm{~g}$ could reduce the overall global burden of disease by $1.8 \%$, and reduce the burden of ischaemic heart disease by $31 \%$, ischaemic stroke by $19 \%$, stomach cancer by $19 \%$, oesophageal cancer by $20 \%$, lung cancer by $12 \%$ and colorectal cancer by $2 \%$ [6].

However, Less than $15 \%$ of the 4 to 8 -year old children consume the recommended servings of FV [7]. Information and food variety influence children's willingness to fruit consumption, but not vegetable

\footnotetext{
*Address correspondence to this author at the School of Public Health, Hamadan University of Medical Sciences, Shaheed Fahmideh Ave. Hamadan, Islamic Republic of Iran, Postal code: 6517838695, PO box: 65175-4171, Iran; Tel: +98 8118380292 ; Fax: +98 8118380509 ;

E-mail: z.hashemi@umsha.ac.ir, hashemi_boshra@yahoo.com
}

consumption [8]. Improving FV consumption in children is a controversial issue. Children are born with a genetic tendency to prefer sweet and to avoid bitter foods such as green leafy vegetables and some fruits $[9,10]$.

The early years of life play an important role in creating healthy eating habits [11]. Higher fruit and vegetables consumption in childhood is associated with the lower risk of stroke and cancer in adulthood [1214]. School is an appropriate setting for healthy eating habits interventions [15-18].

With regard to the expressions about the importance of FV consumption in children, and appropriateness of school setting for presenting these trainings, this study was performed to evaluate school based Interventions that aimed at promoting FV consumption in elementary school students. Past school based reviews about promoting FV consumption in elementary school students did not consider the effectiveness of applied behavior change theories and models. This study evaluates and compares theory and model based interventions with studies that have no specific theoretical framework. This study focuses on the type and quality of trainings like gardening, cooking, educational materials and providing FV at school. 


\section{METHODS}

In this systematic review we evaluated interventions about improving FV consumption in elementary school students in school setting. In these interventions, we focused on study design, intervention strategies, application of behavioral change theories and models and intervention duration. We classified studies into three different categories according to the intervention types: (1) Gardening and education (2) Educational programs (3) Providing FV at school. Some of articles in these three groups are theory or model-based and some of them are without theoretical framework. Also we evaluated the effectiveness of using these theories and models for improving FV consumption in children.

\section{Search Strategy}

Articles were selected through a search in PubMed, Web of Science, Education Resources Information Center (ERIC), Science Direct and Google Scholar. Studies published between January 2005 and December 2012 were included. The following search terms were used in various combinations: Fruits,
Vegetables, Fruit and vegetable, Consumption, Intake, Education, Intervention, School, Elementary school, Children. Articles were limited to those that targeted elementary school students. In this systematic review, we included all Experimental and Quasi-Experimental studies that promoted FV consumption in elementary school setting. Only English language articles were Included. We excluded studies that evaluated interventions to promote fruits or vegetables separately.

\section{Inclusion Criteria}

Reporting the intervention outcomes clearly, considering the improvement of FV consumption as the main objective of the study and considering elementary school students as target group.

\section{Exclusion Criteria}

Improving both physical activity and FV consumption, considering only parents as target group for training, focusing on childhood obesity, performing the intervention only in the case of fruits or vegetables

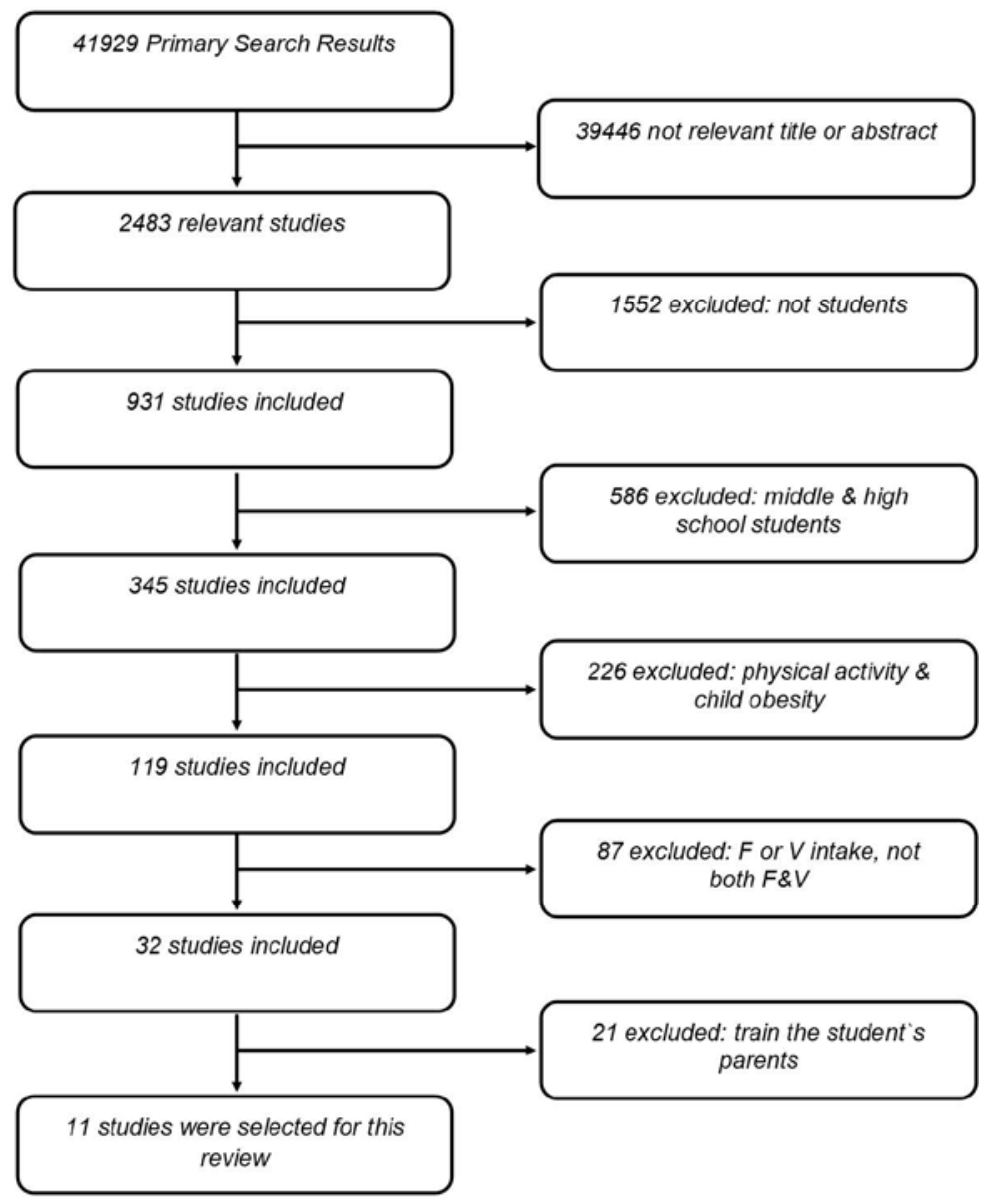

Figure 1: Flow chart of study selection. 
and considering middle or high school students or adults beside elementary school students as target group. To ensure the accuracy of the selected studies, two authors reviewed the inclusion and exclusion criteria independently.

\section{RESULTS}

As shown in (Figure 1), through the search strategy almost 41929 articles were obtained which were reviewed by two researchers to remove non-relevant titles and abstracts. 39446 articles remained to full text relevance checking, 1552 of 2483 remained studies were excluded because students were not their target audiences, 586 were excluded as their intervention was performed in middle or high schools, 226 were excluded as their intervention included improving physical activity or child obesity control. From 119 remained articles, 87 were excluded because the intervention implemented to increasing fruit or vegetable intake, not both of them. 21 studies were excluded because their target groups for training were Students and their parents. Finally, 11 articles were entered into this systematic review.

Considering the importance of FV consumption in children and its impact on the reduction of cardiovascular disease, stroke, cancer and mental disorders, we can say that improving FV consumption in elementary school students at school setting is critical and necessary. Studies were classified into three different categories according to the intervention types: (1) Gardening and educational program (2) Educational programs (3) Providing FV at school.

\section{Overview of Studies}

(Table 1) represents the characteristics of each study, including author, time of intervention and study location, participants, sample size, conceptual framework, educational intervention, study duration and results. The following overview of studies provides more information about methodologies and interventions, and the impact of these interventions on FV consumption in elementary school students.

\section{Gardening and Educational Program}

Wang MC [19], evaluated a school based comprehensive intervention to change school meal services, nutritional condition and experiences of dining, with cooking and gardening interventions, and merge nutrition and food implications into the school curriculum. This study was performed in 3 years on 327 $4^{\text {th }}$ and $5^{\text {th }}$ graders in California. Interventions included school food, school dining, garden classes, cooking classes and lesson integration. At baseline, FV consumption did not vary between schools at different levels of intervention development. There was a notable increase in FV consumption by 0.46 cups $(0.9$ standard servings) among "HIGH" intervention development group in year 2. Much of the increased consumption in "HIGH" group is related to an increase in vegetable intake. Students most exposed to interventions showed an increase of nearly 0.5 standard cups, while students least exposed showed a decrease of 0.3 cups. This increase was largely attributable to vegetable consumption.

Parmer SM [20], examined the effectiveness of a school based gardening program on student's FV knowledge, preference, and consumption. Participants were classified into 3 groups, (1) nutrition education and gardening (NE\&G), (2) nutrition education (NE) only and (3) control group (CG). Intervention groups received classroom instruction and the nutrition education and gardening group also received a gardening program. Paired t-tests showed that the NE\&G group was more willing to test vegetables in the school lunch $(\mathrm{t}=3.19, \mathrm{P}<.01)$. There were two changes in consumption scores. First, the lowest vegetable consumption was in the $C G(t=-2.64, P<$ .001 ) at post-test as compared to the pre-test. Second, vegetable intake in the NE\&G group was significantly higher than that in other groups $(t=3.04, P<.001)$ at post-test as compared to pre-test. The NE group had no significant change in consumption. The intervention groups were indicated a higher willingness to try FV than the control group for ratings of tasted FV by participants. There was a considerable main effect for treatment $[\mathrm{F}(1,75)=17.63, \mathrm{P}<.001]$, as well as a considerable interaction $[F(2,75)=14.45, P<.001)$. Paired t-tests indicated that both treatment groups rated $F V$ significantly better tasting (NE\&G, $t=5.3, P$ $<.001 ; \mathrm{NE}, \mathrm{t}=2.7, \mathrm{P}<.001$ ) at post-test as compared to pre-test than did the $C G(t=1.2, P=.227)$. Results of a mixed-model ANOVA showed significant changes in most parts of nutritional knowledge of participants in intervention groups. This study indicated significant effects of school gardening practices on the nutritional behavior of young children.

Heim $S$ [21], implemented a 12-week pilot intervention to promote FV consumption among $934^{\text {th }}$ to $6^{\text {th }}$ grade children participating a YMCA summer camp. Interventions included garden-based activities twice a week and weekly educational activities 


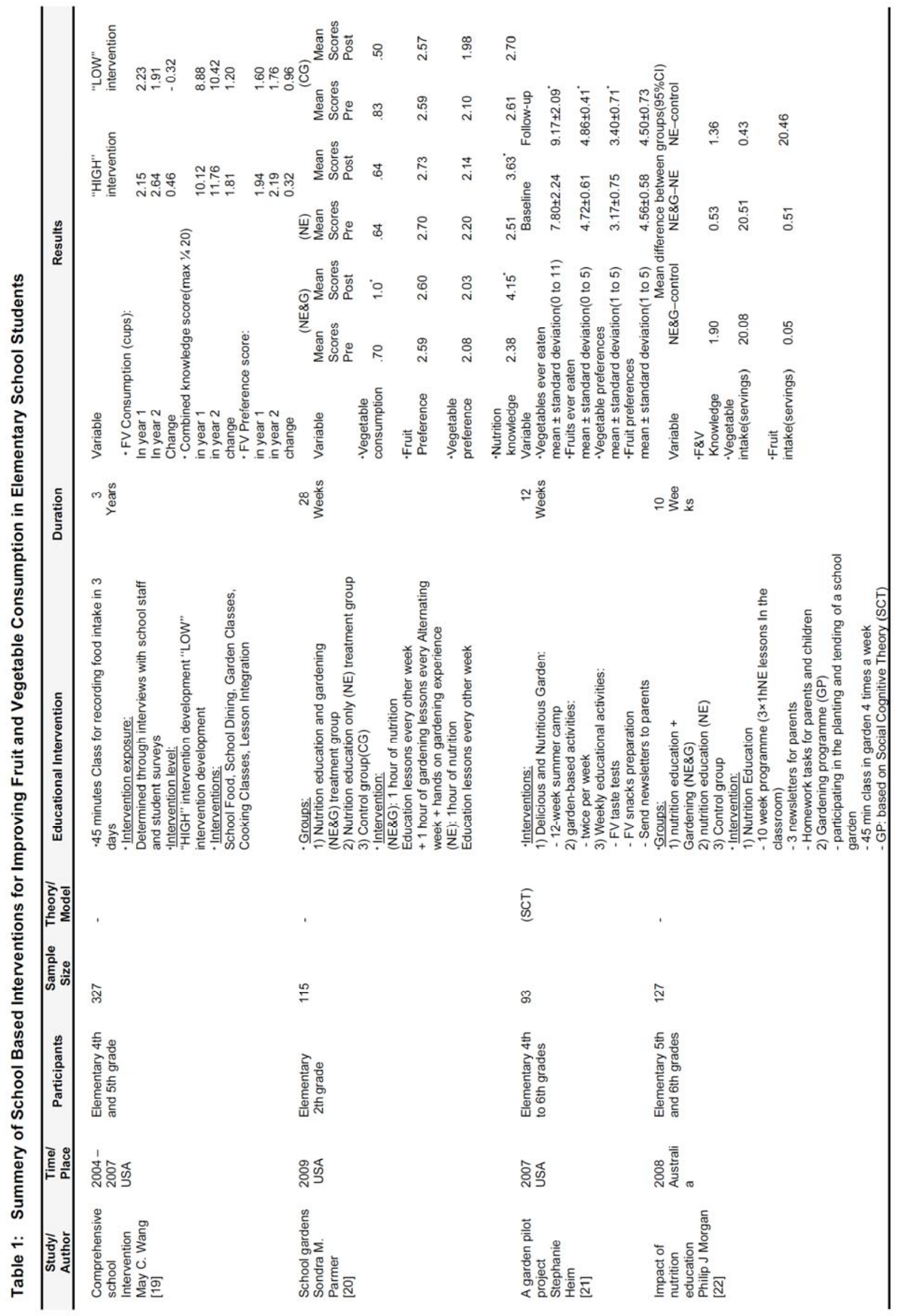




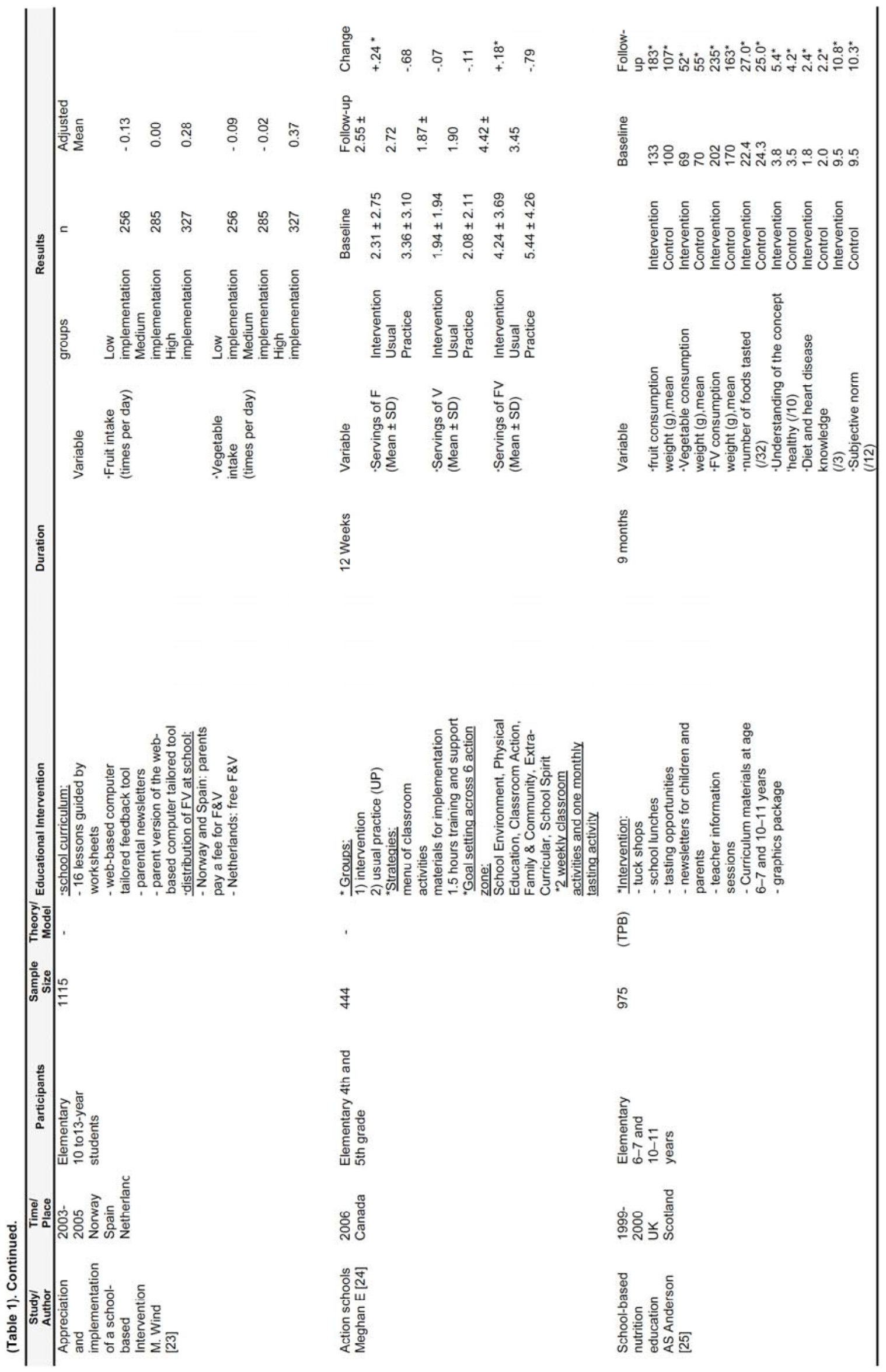




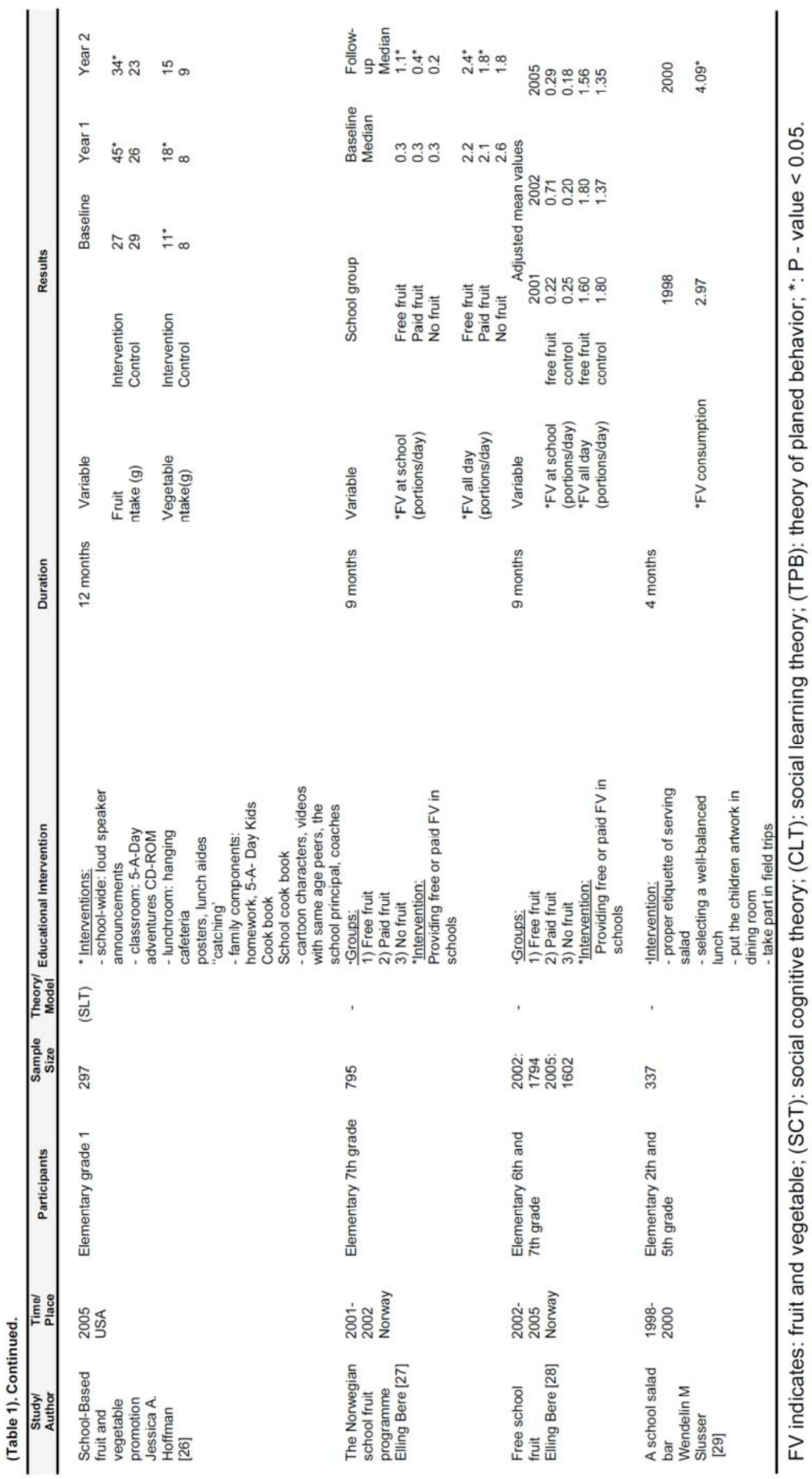


including FV taste-tests, FV snacks preparation, and family newsletters for parents. This program was evaluated using a pre and post survey to specify participant satisfaction and the results of the program. Process data suggest that $(97.8 \%)$ of children enjoyed taste-testing different FV. (93.4\%) of children liked preparing $\mathrm{FV},(95.6 \%)$ liked working in garden and (91.3\%) liked learning about FV. Outcome Measures indicated that children reported a significant increase in the number of eaten FV. Also, there was a significant increase in vegetable preferences. Fruit preferences were high at baseline and stayed without changes from baseline to follow-up. The intervention activities caused the sense of ownership and pride that improved the number of $\mathrm{FV}$ consumption and vegetable preferences.

Morgan PJ [22], performed an Quasi-Experimental 10-week intervention in three groups of 127 , elementary school students in grades 5 and 6 : nutrition education and gardening (NE\&G), nutrition education (NE) and control group (CG). Results showed that the students in the NE\&G and NE gropes significantly were more willing to try vegetables. There was a significant difference for FV knowledge $(P=0.02)$, among the $N E \& G$ and control groups. By comparing students who had fewer knowledge about FV at baseline, the ability to identify vegetables in NE\&G group significantly enhanced $(P=0.001)$ compared with the NE and control groups. There was no significant difference between groups for vegetable consumption $(P=0.22)$ and fruit consumption $(P=0.23)$. Students who worked in the garden were more willing to try the vegetables. NE\&G group students were more willing to use vegetables as snacks.

\section{Educational Programs}

Wind $M$ [23], implemented an intervention to explore the success rate of the comprehensive FV intervention among the 10 to 13-year old children in Norway, Spain and the Netherlands. The intervention included a school curriculum, parental involvement and distribution of $\mathrm{FV}$ at school. The program appreciation $(P<0.01)$ and the success rate in implementing the school curriculum $(P<0.05)$ were significantly related with FV consumption. The greatest increase in consumption was in students that completed $>10$ lessons at school In comparison with those who had done among 7 and 10 lessons $(P<0.05)$ or less than seven lessons $(P<0.05)$. There was a significant association between program appreciation $(P<0.01)$. Parental involvement had a significant impact on student's vegetable intake but had no impact on fruit intake.

Day ME [24], performed this study to evaluate the effectiveness of a school-based FV intervention about: 1) FV consumption, 2) knowledge, attitudes and perceptions about $F V$, and 3 ) willingness to try new $F V$ in students. 246 students from five schools were considered as the intervention group and 198 students from five schools were selected as usual practice (UP) group. The intervention included school-wide activities based on individualized action plans addressing goals across six Action Zones (School Environment, Physical Education, Classroom Action, Family \& Community, Extra-Curricular, School Spirit). Teachers implemented two weekly classroom activities and one monthly tasting activity throughout 12 weeks. There were significant effects for fruit servings, FV variety, and total FV servings. There was a decrease (-.79 serving) at UP schools in FV servings, while a small increase (+.18 serving) was seen at intervention schools. No effects were found for vegetable servings. Knowledge about FV and willingness to try new FV did not change during the time. There was small increase in FV servings compared with other multi-component FV school-based interventions.

Anderson AS [25], assessed the influence of a school-based nutrition education intervention on 975 (511 students: intervention and 464 students: control) elementary school students in Scotland. There was an average increase in fruit consumption in intervention group $(133 \pm 1.9$ to $183 \pm 17.0 \mathrm{~g}$ day) that was significantly higher than that $(100 \pm 11.7$ to $107 \pm 14.2$ $\mathrm{g}$ day) in control group $(\mathrm{P}<.005)$. Factors related to knowledge about FV and subjective norms were higher in intervention group than the control group. Also, taste preferences of FV did not change. Age-adjusted assessments were performed for testing beliefs, attitudes and knowledge about FV, based on the Theory of Planned Behavior.

Hoffman JA [26], explored the long-term effects of a school-based intervention about FV consumption in 297 kindergarten and first grade children. The intervention included school-wide, classroom, lunchroom, and family partnership based on social learning theory (SLT). Also, cartoon characters, same age peer's videos, school principal and trainers were used in intervention. The school-wide part, included announcement broadcast by loudspeaker providing an interesting points about this day's FV. The classroom part included the 5-A-Day stories CD-ROM that was 
presented in computer class. In lunchtime part, posters about this day's FV were hanged in cafeteria and lunch aides encouraged students through verbal praises and giving them stickers about FV. Attractive characters as symbolic role models captured children's attention while standing on the cafeteria line. "caught eating FV" was a reinforcement-based intervention considered as peer role modeling and vicarious learning. The family part included homework, the 5-A-Day kid's cookbook, and a school cook book. Results indicated that FV consumption in intervention group was higher than that in control group $(F=29 \mathrm{~g} ; \mathrm{V}=6 \mathrm{~g} ; 0.43$ portions/lunch; 0.28 servings/lunch) at the end of year 1 . At the end of year 2 in intervention group fruit consumption was more than that in control group $(21 \mathrm{~g} ; 0.23$ portions/lunch; 0.15 servings/lunch), but no significant differences were found in vegetable intake. These results indicate that multi-component school-based programs significantly have long-term effects on children's FV intake behaviors.

\section{Providing FV at School}

Bere E [27], compared the effect of providing daily free fruit or vegetables for Norwegian students at school with a fee-based School intervention. A total of $7957^{\text {th }}$ grade elementary school students participated in this study. Two groups each including 9 schools were considered as intervention groups. One group as free fruit and the other as paid fruit. Twenty no fruit schools participated in this program as control group. There was a significantly higher FV consumption in free fruit group at school than the two other groups ( $P$ $<0.001)$. Paid fruit group had significantly higher FV consumption than no fruit group $(P=0.003)$. The results showed that, free fruit group had a significantly higher all day FV consumption compared to both the paid fruit and the no fruit groups $(P=0.003)$. There were no significant differences between the paid fruit group and the no fruit group in all day FV consumption ( $P=0.58$ ). Free FV program is an effective way to enhance student's FV consumption.

Bere $E$ [28], performed a follow up for the Norwegian School Fruit Programme at 2005. A total of 1794 students in May 2002 and 1602 students in May 2005 participated at the follow-up. There were significant effects, three years after the intervention in FV consumption (all p-values $<0.001$ ). Results showed that free school FV program had a considerable effect on student's FV consumption. Also three years after the intervention the results were significant.
Slusser WM [29], evaluated FV consumption in elementary school students by presentation of a salad bar as a lunch menu option. The salad bar lunch menu option included teaching students about the proper etiquette of salad serving, selecting an appropriate lunch, putting the children's artworks in dining room, and taking part in field trips. There was a significant improvement in the frequency of FV consumption from a mean (standard deviation) of 2.97 to $4.09(\mathrm{P}<0.001)$.

\section{DISCUSSION}

This systematic review evaluated interventional programs about improving FV consumption in elementary school students at school setting. According to our classification of the 11 studies included in this review, four highlighted gardening and cooking in their interventions [19-22]. Gardening and cooking-based educations, with school food environment changes, have a good behavioral impact on FV consumption. Although educational program alone does seem to enhance FV knowledge and preference in elementary school students, adding the gardening factor in intervention strategies strengthens the likelihood of increasing FV intake in this group [19, 20]. Also gardening can impact on student's willingness to try new FV because exposure, in general, has previously been found to be related with increased intake [22, 30-32]. Participating in planting and harvesting creates the sense of ownership and pride that will encourage the students to more FV consumption [21]. Of included studies, four emphasized on educational programs [23, 26]. The degree of implementation of program and children's understanding about trainings are associated with higher FV consumption. Acceptance of the program by students may have been dependent on localized guidelines and programs [23]. If children enjoy the intervention, they will participate in every part of the program. Students prefer more practical trainings such as FV tasting, computer based learning, FV consumption at school and creation a recipe [33]. To ensure ideal implementation of the programs, teachers have to participate in the curriculum development and performance of the program. Furthermore, determinants of implementing the school curriculum have to be considered [23] [26]. Parental influence is one of the most important determinants of children's FV consumption [34-37]. Parental involvement in interventions has to be more extensive [24, 25]. Barriers to the performance of tasting activities included time, money, equipment and resources. 
Teachers need training, consistent support and resources in order to achieve the desired performance [24]. Behavioral change models and theories can be helpful in intervention planning. This can be effective for influencing essential structures in behavioral changes such as improving FV in students. Some of these theories and models that are effective in FV consumption included social learning theory (SLT) [26], social cognitive theory (SCT) [21] and theory of planed behavior (TPB) [25]. Educational methods that can be effective in increasing FV consumption included providing educational CD-ROM, reminder posters, loudspeaker announcements, stickers about the FV and lunch aide's persuasion to try FV [26]. Computerbased interventions have a positive effect on improving FV consumption [38]. The short-term intervention can not be used to demonstrate lifelong changes in eating habits, but does show the ability of an educational program to impact on diet at a crucial life stage when eating habits are being formed. The short-term intervention can not make fundamental changes in children's eating habits but can influence the formation of children's food habits [25]. Exposure increases the food acceptance and tendency to consuming. Thus, interventions for improving $\mathrm{FV}$ consumption have a positive effect on increasing the likelihood of tasting new FV [25, 27, 30]. Availability of free FV is an effective approach to increasing FV consumption in children [28, 29]. Increasing vegetable consumption in all ages at different social levels is one of the challenges for health and nutrition professionals [25, 39]. In most of FV intake interventions, there is a significant increase in fruit consumption, but there is no significant increase in vegetable consumption. Therefore, we have to plan extensive interventions to promote vegetable consumption in elementary school students. To identify effective educational and interventional methods to improving vegetable consumption, qualitative studies can be used.

\section{CONCLUSIONS AND IMPLICATIONS}

In this systematic review, we evaluated 11 interventions about improving $\mathrm{FV}$ consumption in elementary school students. According to the results, we found that interventions about improving FV consumption in these three classifications (gardening and education, educational programs and providing $\mathrm{FV}$ at school) have positive effects on children's intake. According to the literature review there are some strategies for increasing FV consumption in these three classifications: (1) Gardening strategies: included participating in hands-on gardening experiences (weeding, watering and harvesting), engaging in gardening challenges (managing pests) and preparing a party by serving the produce they have grown. (2) Educational strategies: included nutrition education classes that can be held by classroom teachers (about the origin of foods, plant parts, nutrient needs of humans and food pyramid), electronic learning as using CD-ROM and computer based learning, a series of newsletters for parents about eating FV, strategies to improve family awareness and promote familial discussion about healthy food choices and homework tasks for parents and children. (3) Providing strategies: included providing free $\mathrm{FV}$ at school is an effective strategy to increase school children's FV consumption. The results show that gardening and educational programs together, are more effective in student's willingness, preference and intake of FV than other cases. After reviewing these articles, we found that using a multi-component strategy (education, gardening and providing FV) is the best way to design and plan an intervention for increasing $\mathrm{FV}$ consumption in elementary school students. A multi-component intervention has positive effects on student's knowledge, attitude and willingness for FV consumption. We can use education, gardening and proving $\mathrm{FV}$, strategies together in an intervention to achieve better results in promoting student's FV consumption, but increasing vegetable intake is more difficult than fruit intake, because fruits are more attractive and delicious for children. To reach the expected results in vegetable intake as fruit intake, initially we have to use multiple strategies to have positive impact on students' attitudes about eating vegetables. Because increasing $F V$ intake is a behavioral change, behavioral change models and theories can be used in designing the interventions. Planning, implementing and monitoring processes based on theory or model are more likely to succeed than those developed without theoretical frameworks. School-based programs for increasing FV consumption that are based on a theoretical framework are more effective at changing health behaviors than non theoretical programs.

\section{ACKNOWLEDGEMENTS}

We would like to thank Public Health School of Hamadan University of Medical Sciences for their valuable collaboration with this study.

\section{COMPETING INTERESTS}

None declared. 


\section{REFERENCES}

[1] Leenders M, Sluijs I, Ros MM, Boshuizen HC, Siersema PD, Ferrari $\mathrm{P}$, et al. Fruit and vegetable consumption and mortality: European prospective investigation into cancer and nutrition. Am J Epidemiol 2013; 178: 590-602. http://dx.doi.org/10.1093/aje/kwt006

Park SY, Ollberding NJ, Woolcott CG, Wilkens LR, Henderson BE, Kolonel LN. Fruit and Vegetable Intakes Are Associated with Lower Risk of Bladder Cancer among Women in the Multiethnic Cohort Study. J Nutr 2013; 143: 1283-92.

http://dx.doi.org/10.3945/jn.113.174920

[3] Larsson SC, Virtamo J, Wolk A. Total and specific fruit and vegetable consumption and risk of stroke: a prospective study. Atherosclerosis 2013; 227: 147-52.

http://dx.doi.org /10.1016/j.atherosclerosis.2012.12.022

[4] Crowe FL, Roddam AW, Key TJ, Appleby PN, Overvad K, Jakobsen MU, et al. Fruit and vegetable intake and mortality from ischaemic heart disease: results from the European Prospective Investigation into Cancer and Nutrition (EPIC)Heart study. Eur Heart J 2011; 32: 1235-43. http://dx.doi.org/10.1093/eurhearti/ehq465

McMartin SE, Jacka FN, Colman I. The association between fruit and vegetable consumption and mental health disorders: evidence from five waves of a national survey of Canadians. Prev Med 2013; 56: 225-30.

http://dx.doi.org/10.1016/j.ypmed.2012.12.016

[6] Lock K, Pomerleau J, Causer L, Altmann DR, McKee M. The global burden of disease attributable to low consumption of fruit and vegetables: implications for the global strategy on diet. Bull World Health Organ 2005; 83: 100-8.

[7] Guenther PM, Dodd KW, Reedy J, Krebs-Smith SM. Most Americans eat much less than recommended amounts of fruits and vegetables. J Am Diet Assoc 2006; 106: 1371-9. http://dx.doi.org /10.1016/j.jada.2006.06.002

[8] Osborne CL, Forestell CA. Increasing children's consumption of fruit and vegetables: does the type of exposure matter? Physiol Behav 2012; 106: 362-8. http://dx.doi.org /10.1016/j.physbeh.2012.01.006

[9] Rosenstein D, Oster H. Differential facial responses to four basic tastes in newborns. Child Dev 1988; 59: 1555-68.

[10] Steiner JE. Facial expressions of the neonate infant indicating the hedonics of food related chemical stimuli. In: Weiffenbach JM, editor. Taste and Development: The genesis of sweet preference. Washington DC: Government Printing Office 1977; p. 173-89.

[11] Birch LL. Development of food preferences. Annu Rev Nutr 1999; 19: 41-62. http://dx.doi.org/10.1146/annurev.nutr.19.1.41

[12] Ness AR, Maynard M, Frankel S, Smith GD, Frobisher C, Leary SD, et al. Diet in childhood and adult cardiovascular and all cause mortality: the Boyd Orr cohort. Heart 2005; 91 : 894-8. http://dx.doi.org /10.1136/hrt.2004.043489

[13] Maynard M, Gunnell D, Emmett P, Frankel S, Davey Smith G. Fruit, vegetables, and antioxidants in childhood and risk of adult cancer: the Boyd Orr cohort. J Epidemiol Community Health 2003; 57: 218-25.

[14] He FJ, Nowson CA, MacGregor GA. Fruit and vegetable consumption and stroke: meta-analysis of cohort studies. Lancet 2006; 367: 320-6.

http://dx.doi.org /10.1016/s0140-6736(06)68069-0

[15] Ribeiro RQ, Alves L. Comparison of two school-based programmes for health behaviour change: the Belo Horizonte Heart Study randomized trial. Public Health Nutr 2013: 1-10. http://dx.doi.org/10.1017/s1368980013000189

[16] Wengreen HJ, Madden GJ, Aguilar SS, Smits RR, Jones BA. Incentivizing children's fruit and vegetable consumption: results of a United States pilot study of the Food Dudes Program. J Nutr Educ Behav 2013; 45: 54-9. http://dx.doi.org/10.1016/i.jneb.2012.06.001

[17] Ungar N, Sieverding M, Stadnitski T. Increasing fruit and vegetable intake. "Five a day" versus "just one more". Appetite 2013; 65: 200-4. http://dx.doi.org/10.1016/j.appet.2013.02.007

[18] Llargues E, Franco R, Recasens A, Nadal A, Vila M, Perez $\mathrm{MJ}$, et al. Assessment of a school-based intervention in eating habits and physical activity in school children: the AVall study. J Epidemiol Community Health 2011; 65: 896901. http://dx.doi.org /10.1136/jech.2009.102319

[19] Wang MC, Rauzon S, Studer N, Martin AC, Craig L, Merlo C, et al. Exposure to a comprehensive school intervention increases vegetable consumption. J Adolesc Health 2010; 47: 74-82. http://dx.doi.org/10.1016/j.jadohealth.2009.12.014

[20] Parmer SM, Salisbury-Glennon J, Shannon D, Struempler B. School gardens: an experiential learning approach for a nutrition education program to increase fruit and vegetable knowledge, preference, and consumption among secondgrade students. J Nutr Educ Behav 2009; 41: 212-7. http://dx.doi.org/10.1016/j.jneb.2008.06.002

[21] Heim S, Stang J, Ireland M. A garden pilot project enhances fruit and vegetable consumption among children. J Am Diet Assoc 2009; 109: 1220-6. http://dx.doi.org/10.1016/j.jada.2009.04.009

[22] Morgan PJ, Warren JM, Lubans DR, Saunders KL, Quick GI, Collins CE. The impact of nutrition education with and without a school garden on knowledge, vegetable intake and preferences and quality of school life among primary-school students. Public Health Nutr 2010; 13: 1931-40. http://dx.doi.org/10.1017/s1368980010000959

[23] Wind M, Bjelland M, Perez-Rodrigo C, Te Velde SJ, Hildonen $\mathrm{C}$, Bere $\mathrm{E}$, et al. Appreciation and implementation of a school-based intervention are associated with changes in fruit and vegetable intake in 10- to 13-year old schoolchildren--the Pro Children study. Health Educ Res 2008; 23: 997-1007. http://dx.doi.org /10.1093/her/cym078

[24] Day ME, Strange KS, McKay HA, Naylor PJ. Action schools! BC--Healthy Eating: effects of a whole-school model to modifying eating behaviours of elementary school children. Can J Public Health 2008; 99: 328-31.

[25] Anderson AS, Porteous LE, Foster E, Higgins C, Stead M, Hetherington $\mathrm{M}$, et al. The impact of a school-based nutrition education intervention on dietary intake and cognitive and attitudinal variables relating to fruits and vegetables. Public Health Nutr 2005; 8: 650-6.

[26] Hoffman JA, Franko DL, Thompson DR, Power TJ, Stallings VA. Longitudinal behavioral effects of a school-based fruit and vegetable promotion program. J Pediatr Psychol 2010; 35: $61-71$. http://dx.doi.org/10.1093/ipepsy/isp041

[27] Bere E, Veierod MB, Klepp KI. The Norwegian School Fruit Programme: evaluating paid vs. no-cost subscriptions. Prev Med 2005; 41: 463-70. http://dx.doi.org/10.1016/j.ypmed.2004.11.024

[28] Bere E, Veierod MB, Skare O, Klepp KI. Free School Fruitsustained effect three years later. Int $\mathrm{J}$ Behav Nutr Phys Act 2007; 4: 5.

http://dx.doi.org/10.1186/1479-5868-4-5

[29] Slusser WM, Cumberland WG, Browdy BL, Lange L, Neumann C. A school salad bar increases frequency of fruit and vegetable consumption among children living in lowincome households. Public Health Nutr 2007; 10: 1490-6. http://dx.doi.org/10.1017/s1368980007000444 
[30] Schindler JM, Corbett D, Forestell CA. Assessing the effect of food exposure on children's identification and acceptance of fruit and vegetables. Eat Behav 2013; 14: 53-6. http://dx.doi.org/10.1016/j.eatbeh.2012.10.013

[31] Hartman H, Wadsworth DP, Penny S, van Assema P, Page R. Psychosocial determinants of fruit and vegetable consumption among students in a New Zealand university. Results of focus group interviews. Appetite 2013; 65: 35-42. http://dx.doi.org/10.1016/j.appet.2013.02.005

[32] Krolner R, Rasmussen M, Brug J, Klepp KI, Wind M, Due P. Determinants of fruit and vegetable consumption among children and adolescents: a review of the literature. Part II: qualitative studies. Int J Behav Nutr Phys Act 2011; 8: 112. http://dx.doi.org/10.1186/1479-5868-8-112

[33] Bere E, Klepp KI. Changes in accessibility and preferences predict children's future fruit and vegetable intake. Int $\mathrm{J}$ Behav Nutr Phys Act 2005; 2: 15. http://dx.doi.org/10.1186/1479-5868-2-15

[34] Rasmussen M, Krolner R, Klepp KI, Lytle L, Brug J, Bere E, et al. Determinants of fruit and vegetable consumption among children and adolescents: a review of the literature. Part I: Quantitative studies. Int J Behav Nutr Phys Act 2006; 3: 22.

http://dx.doi.org /10.1186/1479-5868-3-22
[35] Blanchette L, Brug J. Determinants of fruit and vegetable consumption among 6-12-year-old children and effective interventions to increase consumption. J Hum Nutr Diet 2005; 18: 431-43.

http://dx.doi.org/10.1111/j.1365-277X.2005.00648.x

[36] Wind M, de Bourdeaudhuij I, te Velde SJ, Sandvik C, Due P, $\mathrm{Klepp} \mathrm{KI}$, et al. Correlates of fruit and vegetable consumption among 11-year-old Belgian-Flemish and Dutch schoolchildren. J Nutr Educ Behav 2006; 38: 211-21. http://dx.doi.org/10.1016/j.jneb.2006.02.011

[37] Patrick $H$, Nicklas TA. A review of family and social determinants of children's eating patterns and diet quality. $J$ Am Coll Nutr 2005; 24: 83-92.

[38] Delgado-Noguera M, Tort S, Martinez-Zapata MJ, Bonfill X Primary school interventions to promote fruit and vegetable consumption: a systematic review and meta-analysis. Prev Med 2011; 53: 3-9. http://dx.doi.org/10.1016/j.ypmed.2011.04.016

[39] Evans CE, Christian MS, Cleghorn CL, Greenwood DC Cade JE. Systematic review and meta-analysis of schoolbased interventions to improve daily fruit and vegetable intake in children aged 5 to $12 \mathrm{y}$. Am J Clin Nutr 2012; 96: 889-901.

http://dx.doi.org/10.3945/ajcn.111.030270 